\title{
CAN TIGHT NECKTIE BE A RISK FACTOR IN DEVELOPMENT AND PROGRESSION OF PRIMARY- OPEN ANGLE GLAUCOMA (POAG)?
}

\author{
BY
}

AJAYI, O. B., AKPOROBARO, N. AND AKINLABI, A. G. DEPARTMENT OF OPTOMETRY, UNIVERSITY OF BENIN, BENIN-CITY, NIGERIA.

Email: ajayiob@yahoo.com

*Corresponding author

\begin{abstract}
Tight neckties have been documented to alter intraocular pressure (IOP) and thus may be a risk factor in the development and progression of primary open angle glaucoma (POAG). Many professionals and white- collar jobs require the use of neckties for the greater part of the day. Tight neckties wearers are unaware of its effect on intraocular pressure and glaucoma. This study investigated the effect of tight neckties on intraocular pressure (IOP) measurement using Perkins applanation tonometry method. Eighty eyes of normal 40 subjects and 40 primary open angle glaucoma patients were enrolled. IOP, blood pressure and pulse rate were measured with an open shirt collar and 5 minutes after placing a tight necktie. All measurements were made by the same examiner. The results showed significant $(\mathrm{P}<0.05)$ increase of IOP after a tight necktie in both groups, irrespective of sex. Thus optometrists should advice patients to remove tight neckties before IOP measurements.
\end{abstract}

KEYWORDS: Necktie, Open angle glaucoma, Applanation tonometry,

\section{INTRODUCTION}

The workforce of a nation comprise mostly of young/ middle-age persons in 'white collar' jobs. Many professional and white-collar jobs for example, bankers, doctors, fuel attendants and lawyers require the use of neckties for the greater part of the day. Some men prefer to wear neckties. In case of females, some wear turtle or high neck blouses due to weather, religious or personal preferences. They are impeccably dressed in suits and necktie during office hours, which span about 8hours daily for about five days out of seven days of the week. This workforce on whose shoulders the economic power of a nation rest may therefore be invariably exposed to the risk of developing glaucoma in the event that their necktie is tight. The glaucomas are a group of diseases characterized by optic neuropathy, characteristic visual field changes with or without elevated intraocular pressure.

Quigley ${ }^{1}$ rated glaucoma as the second leading cause of vision loss worldwide. He also estimated that 66.8 million people are affected by glaucoma worldwide and 6.7 million are bilaterally blind because of the disease. It was said to affect individuals of all age groups but is more prevalent after the fourth decade of life. Black subjects, in comparison with Caucasian subjects, are known to have increased risk of optic nerve damage caused by glaucoma ${ }^{2}$.

Increase in intraocular pressure occurs when there is a build up of pressure due to poor outflow of aqueous humor. The outflow obstruction could occur at the trabecular meshwork of the anterior chamber angle or subsequently in the episcleral vein due to raised venous pressure. Such build up of pressure results in glaucoma ${ }^{3}$.

Elevated intraocular pressure remains the most important known risk factor for the development and progression of glaucomatous damage. Ajayi and Otoide ${ }^{4}$ in order to assess visual health status through physiological changes investigated the effect of exercise on IOP in a Nigerian community. The experiment involved mild hypertensive and normotensive subjects. Both groups were subjected to the same standardized exercise. The result showed significant decrease in IOP after exercise, irrespective of systemic blood pressure or sex.

Dane et $\mathrm{al}^{5}$ studied sex related differences in intraocular pressures of the right and left eyes of 64 men and 61 women. He found that intraocular pressure of both eyes were higher for women than men. He concluded that the sex related difference in intraocular pressure might be associated with the presence of the sex hormone; oestrogen in women 
that reduces sympathetic activity.

Ajayi et $\mathrm{al}^{6}$ investigated the relationship between blood pressure, ocular perfusion pressure and glaucoma in the Nigerian population. One hundred and twenty one eligible diabetic and sickle cell free volunteers (59 males and 62 females) were recruited for the study. The subjects were screened for glaucoma. Also the blood pressure was taken and the mean perfusion pressure (PPm) was then calculated. Results showed that low perfusion pressure was strongly associated with both high and low tension glaucoma $(\mathrm{P}<0.05)$. Also, low systolic and diastolic BP was found in the younger age group (40-44years). It was concluded that relatively low arterial blood pressure might be a risk factor for low tension glaucoma.

Goldberg $^{7}$ reported that intraocular pressure (IOP) correlates with progressive loss of visual field in patients with glaucoma. He also noted that lowering of IOP has been proven to reduce progressive loss of the visual field in glaucoma subjects.

This study therefore sets out to:

Investigate the possible effect of tight necktie on intraocular pressure of normal subjects and primary open angle glaucoma patients.

ii Determine if any; the effect of tight necktie on intraocular pressure are gender biased.

iii Advocate educational enlightenment on the possibility of tight neckties in endangering vision.

This study was faced with the following limitations: the tightness of the necktie could not be made uniform in all subjects used; it was difficult in convincing the subjects to leave their place of work or home in order to be at the clinic; getting subjects (POAG patients) who are willing to tie the necktie, especially the older subjects and limited finance and time to enable the examiner visit more hospitals and organizations to acquire more data.

\section{MATERIALS AND METHOD}

This study is a prospective clinical trial in which the effect of a tight necktie on intraocular pressure (IOP) was evaluated, using normal subjects and primary open angle glaucoma patients (POAG). A total number of 80 people (40 normal subjects and 40 POAG patients) were enrolled in the study. Informed consent was obtained from each subject before enrolment. The normal subjects were selected from professionals (e.g. bankers, lawyers, and fuel attendants) who wore collared shirts and had best corrected visual acuity of $6 / 6$ or better. Subjects were excluded if they had current infection or inflammation in eye, strabismus, and previous incisional glaucoma filtration surgery. All normal subjects had IOP $<21$ $\mathrm{mmHg}$ by Perkins applanation tonometry, normal optic disc appearance based on opthalmoscopy and Bjerrum visual field. POAG patients were selected from confirmed glaucoma patients of the Lagos State University Teaching Hospital. The patients had glaucomatous optic nerve damage and associated visual field loss.

Sphygmomanometer was used for measuring the systolic and diastolic blood pressure. Accoson's sphygmomanometer was used in this study. The blood pressure was measured on the right hand of the subjects only.

Subjects were seated comfortably in an examination chair in all times. The pulse rate and blood pressure were measured from the right hand of the subjects. One drop of novesine ${ }^{\circledast}$ (topical anesthetic agent) was instilled in each eye and stained with fluorets ${ }^{\circledast}$ (Chauvin pharmaceuticals L td, Harold Hill, Romford, Essex England): fluorescein sodium BP $1 \mathrm{mg}$ strips before tonometry. Two consecutive IOP readings in each eye were taken and the average reading was recoded. The necktie was then placed around the neck and tightened to a point slight discomfort. The IOP, pulse rate and blood pressure were again measured 5 minutes later.

\section{RESULTS}

This study was carried out at both Lagos State Teaching Hospital, Ikeja (LASUTH) and Fulview Eye Clinic, a total of 80 subjects participated. 40 primary open angle glaucoma patients (POAG) were selected from LASUTH while 40 normal subjects were also selected and enrolled from both Triumph Bank and Union Bank.

In the above distribution, it shows that the normal males had $33.75 \%$; normal females $16.25 \%$; POAG male $30 \%$ and POAG female had $20 \%$. Table 1 shows the mean value (SD) of data 


\section{AJAY, O. B. AKPOROBARO, N. AND AKINLABL, A. C.}

collected before and after a necktie. It shows that the mean systolic and diastolic pressure before the necktie for normal patients was $123.95 \mathrm{mmHg}$ and $83.50 \mathrm{mmHg}$ and that of the POAG patients were $126.55 \mathrm{mmHg}$ and $85.00 \mathrm{mmHg}$ respectively .

These values are within the normal blood pressure range suggesting that all the participants were tested under normal conditions free from external factors like stress.

The mean IOPs before the necktie for normal males and females were $14.31 \mathrm{mmHg}$ and $13.77 \mathrm{mmHg}$ respectively while that of the POAG male and females were $17.64 \mathrm{mmHg}$ and $17.56 \mathrm{mmHg}$ respectively. After a tight necktie, the mean IOPs for normal males and females were $15.40 \mathrm{mmHg}$ and $14.50 \mathrm{mmHg}$ respectively, POAG males and females were $18.71 \mathrm{mmHg}$ and $18.94 \mathrm{mmHg}$ respectively.

Using the paired test to assess the mean increase in IOP before and after a tight necktie; the increase was found to be statistically significant in the normal males, $\mathrm{t}=3.921$ and $\mathrm{P}<0.05$; normal females $\mathrm{t}=1.287$ and $\mathrm{P}<0.05$; POAG males $\mathrm{t}=$ 2.970 and $<0.05$; POAG females $t=2.933$ and $\mathrm{P}<0.05$.

The mean differences of data before and after the necktie were further classified according to ages. An increase in IOP was observed after a tight necktie in all ages for the normal subjects. The POAG patients also had an increase in IOP in most ages expect the ages 36-40 which experienced no change (fig. 2)

\section{DISCUSSION}

The effect of posture on the level of IOP was eliminated in this study since all IOP measurements were made with subjects in the sitting position. Blood pressure and pulse rates were also measured in the study but these were used only for monitoring the condition of the subjects. The blood pressure and IOP were not measured at the same time since IOP is affected when pressure is applied to the arm by the sphygmomanometer cuff ${ }^{8}$.

In this study, the 5 minutes time interval was chosen as an estimation of the time it takes to physiologically respond to the tightening of the necktie. Therefore, whether or not, auto regulation would have brought the pressure down if the necktie had been left on for a little longer or whether the data would differ if the time interval was different remains to be determined. Moreover, a follow up study using Tonopen when the patients were resting comfortably would answer the question of whether the act of leaning forward with a tight necktie for Perkins applannation tonometry further raises IOP.

A tight necktie caused a significant increase in IOP in both the normal subjects and the POAG patients (Paired $\mathrm{t}=3.741, \mathrm{P}<0.05$ ) according to findings of an earlier study ${ }^{9}$. In terms of gender, there was a mean increase of $1.09 \mathrm{mmHg}$ with standard deviation of 1.45 and a mean increase of $0.73 \mathrm{mmhg}$ with standard deviation 2.05 among normal male and female subjects respectively. In the case of the POAG patients, there was a mean increase of $1.06 \mathrm{mmHg}$ with standard deviation of 1.75 and a mean increase of $1.38 \mathrm{mmHg}$ with standard deviation of 1.88 among males and females respectively.

However, these increases in IOP were not significantly different. Also in terms of ages, an increase was observed in all age categories studied. This has shown that IOP increase due to a tight necktie was irrespective of age.

In the normal subjects, $74 \%$ had an increase in IOP, $11 \%$ had no change and $15 \%$ had a decrease in IOP. In POAG patients, $74 \%$ had an increase, $14 \%$ had no change and $12 \%$ experienced a decrease. Generally the results of this study are in agreement with the findings of previous studies that reported an increase in IOP following a tight necktie. Teng et $\mathrm{al}^{9}$ found that a tight necktie increased IOP in both normal subjects and glaucoma patients and could affect the diagnosis and management of glaucoma. Five minutes of necktie tightening had shown an increase in IOP but its long term effects (especially during working hours) on IOP are yet to be studies.

A number of factors can lead to an elevated IOP but the mechanism for the increased IOP observed in this study is a neck compression caused by the tight necktie. The neck compression constricts the internal jugular vein thereby causing elevated venous pressure, and thus elevated episcleral venous pressure, in turn elevating IOP. Not all subjects experienced an increase in pressure after tightening; some even had a decrease. Thus unexpected result might be attributable to 


\section{AVAY, 0. B, ATPOBOBARO, N, AND AYTINLABI, A.G.}

anatomical variation and possibly a baroreceptor reflex. Normal deviation from the mean must also be taken into account. The results, when further classified into ages also showed an increase in all ages. This therefore demonstrates that the tight necktie is a common and overlooked risk factor for increased IOP and a confounder for accurate IOP measurement.

Subsequently, we recommend the effective educational enlightenment on the populace on the possibility of tight necktie endangering vision. Organization of public lectures through the mass media, television and radio programs and articles in the local newspapers can go a long way in helping to educate the populace. Special emphasis should be directed to those who wear necktie regularly or tight clothing around the neck (white collar professionals).

It is also recommended that clinicians should make sure that factors like a necktie, which could lead to an erroneous IOP measurement and therefore a misdiagnosis or mismanagement, should be eliminated during examination.

\section{ACKNOWLEDGEMENT}

The authors wish to acknowledge the professional assistance and constructive criticisms of Dr. B. Balogun.

TABLE 1: MEAN VALUES OF DATA COLLECTED BEFORE AND 5 MINUTES AFTER A TIGHT NECKTIE.

\begin{tabular}{|l|l|l|l|l|}
\hline \multirow{2}{*}{ Groups } & \multicolumn{5}{c|}{ Before } \\
\cline { 2 - 5 } & $\begin{array}{l}\text { Pulse rate } \\
\text { Mean } \pm \text { (SD) }\end{array}$ & $\begin{array}{l}\text { Systolic Pressure } \\
\pm(\text { SD) }\end{array}$ & $\begin{array}{l}\text { Diastolic } \\
\text { Pressure } \\
\pm \text { (SD) }\end{array}$ & $\begin{array}{l}\text { IOP } \\
\text { Pressure } \\
\pm \text { (SD) }\end{array}$ \\
\hline Total normal & $60.95 \pm 3.82$ & $123.95 \pm 5.84$ & $83.50 \pm 5.54$ & $14.14 \pm 1.97$ \\
\hline Total POAG & $59.93 \pm 6.57$ & $126.55 \pm 6.67$ & $85.00 \pm 6.36$ & $17.61 \pm 3.28$ \\
\hline Normal Male & $61.82 \pm 3.53$ & $125.04 \pm 5.64$ & $84.81 \pm 5.33$ & $14.31 \pm 2.11$ \\
\hline Normal Female & $59.15 \pm 3.89$ & $121.69 \pm 5.82$ & $80.77 \pm 5 . .12$ & $13.77 \pm 1.65$ \\
\hline POAG male & $59.33 \pm 6.64$ & $127.58 \pm 7.00$ & $85.50 \pm 6.33$ & $17.64 \pm 3.18$ \\
\hline POAG Female & $60.81 \pm 6.57$ & $125.00 \pm 6.07)$ & $84.25 \pm 6.53$ & $17.56 \pm 3.54$ \\
\hline \multicolumn{5}{|c|}{ AFTER } \\
\hline Total normal & $62.10 \pm 3.58$ & $127.45 \pm 6.16$ & $85.55 \pm 5.19$ & $15.11 \pm 2.15$ \\
\hline Total POAG & $61.33 \pm 6.51$ & $128.95 \pm 7.06$ & $85.40 \pm 6.77$ & $18.80 \pm 3.68$ \\
\hline Normal Male & $62.85 \pm 3.22$ & $127.48 \pm 6.07$ & $86.74 \pm 5.12$ & $15.40 \pm 2.39$ \\
\hline Normal Female & $60.54 \pm 3.91$ & $127.38 \pm 6.60$ & $83.08 \pm 4.59$ & $14.50 \pm 1.68$ \\
\hline POAG male & $61.25 \pm 6.58$ & $129.50 \pm 7.08$ & $85.42 \pm 6.61$ & $18.71 \pm 3.61$ \\
\hline POAG Female & $61.44 \pm 6.60$ & $128.13 \pm 7.17$ & $85.38 \pm 7.22$ & $18.94 \pm 3.92$ \\
\hline
\end{tabular}

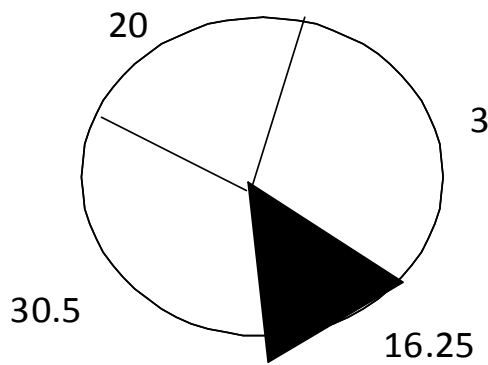

33.75

Normal Males (33.75\%)

Normal Females(16.25\%)

POAG Males $(30.50 \%)$

POAG Females (20\%)

FIG. 1: DISTRIBUTION OF PARTICIPANTS IN THIS STUDY 


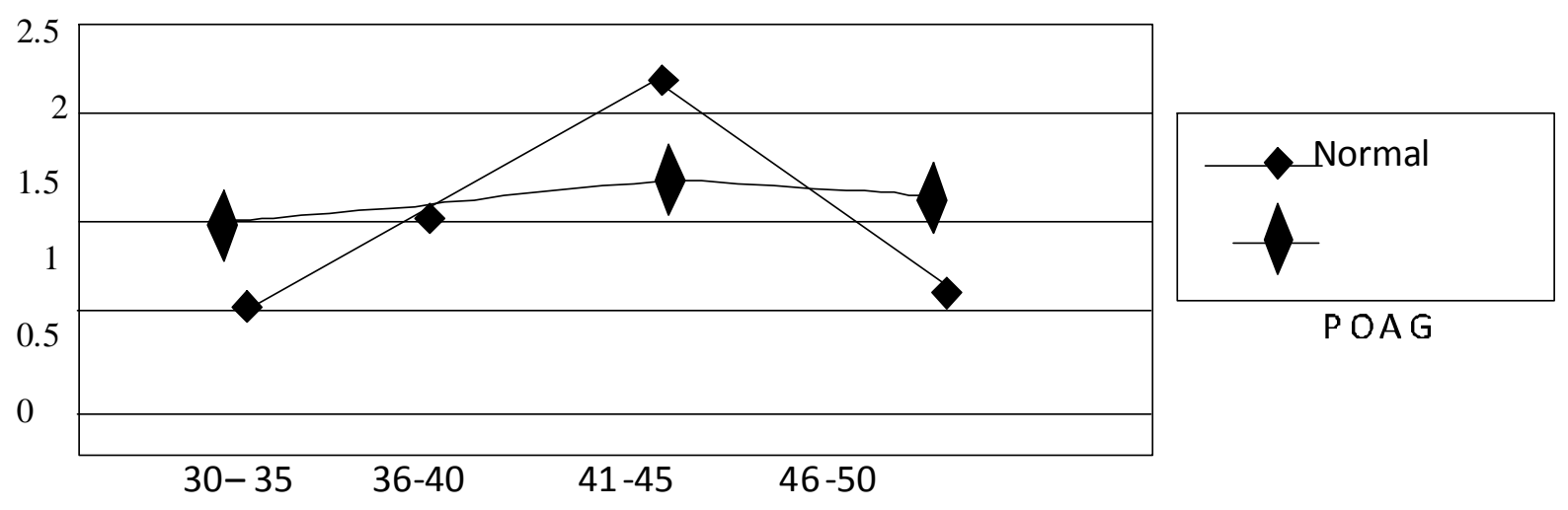

FIG 2: MEAN DIFFERENCE IN IOP IN NORMAL AND POAG SUBJECTS

\section{R E F E R E N C E S}

1. Qiugley, H. A. (1996): Number of people with glaucoma worldwide. Br. J. Ophthalmol, 69: 664-7.

2. Leske, M. C., Connell, A. M., Wu, S. Y., Hyman, L. and Schachat A. P. (1995): Open angle glaucoma: The Barbados eye study. Arch. Ophthamol, 115 (8):1057-67.

3. Kishore, K. I. (2002) Tobacco and intraocular pressure. J. Hlth. Allied Scis, 3:1

4. Ajayi, O. B. and Otoide, P. E. (2000): Short term effect of exercise in intraocular pressure in a Nigeria population. S. Afr. Optom,59(3): 78-82.

5. Dane, S., Aslankurt, M., Yazici, A. T. and Gumustekin, K. (2003): Sex-related difference in intraocular pressure in healthy young subjects. Percept Mot. Skills, 963(2): 1314-6.
6. Ajayi, O. B., Iyawe, V. and Ewah, P. I. (2002): Blood pressure and ocular perfusion pressure in primary open angle glaucoma in the Nigerian population. S. Afr. Optom, 61(4):167-70.

7. Goldberg, I. (2003): Relationship between intraocular pressure and preservation of visual field in glaucoma. Surv. Ophthamol, 48(Suppl): 1:53-7.

8. Buchanan, R. A. and Williams, T. D. (1985): Intraocular Pressure, pulse pressure and body position. Am. J. Optom. Physiol. Opt, 62: 5460.

9. Tang, C. R., Gurses-Ozden, O., Liebmann, J. M., Tello, C. and Ritch, R. (2003): Effect of tight necktie on intraocular pressure. Br. J. Ophthalmol, 87(8) 946. 